\title{
Control of the Shunt Active Power Filter under Non-ideal Grid Voltage and Unbalanced Load Conditions
}

\author{
Samet Biricik \\ Technological University Dublin \\ Soydan Redif \\ European University of Lefke (Cyprus) \\ Ozgur Ozerdem \\ Near East University - Cyprus
}

See next page for additional authors

Follow this and additional works at: https://arrow.tudublin.ie/engscheleart

Part of the Electrical and Electronics Commons

\section{Recommended Citation \\ This Conference Paper is brought to you for free and open access by the School of Electrical and Electronic Engineering at ARROW@TU Dublin. It has been accepted for inclusion in Conference papers by an authorized administrator of ARROW@TU Dublin. For more information, please contact arrow.admin@tudublin.ie, aisling.coyne@tudublin.ie,gerard.connolly@tudublin.ie. Funder: European Commission}

Biricik, S.; Redif, S.; Ozerdem, O.C.; Basu, M., "Control of the shunt Active Power Filter under non-ideal grid voltage and unbalanced load conditions," Power Engineering Conference (UPEC), 2013 48th International Universities' , vol., no., pp.1,5, 2-5 Sept. 2013 doi: 10.1109/UPEC.2013.6715008

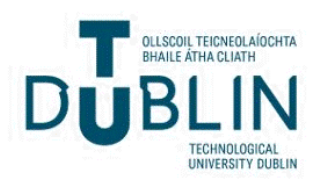




\section{Authors}

Samet Biricik, Soydan Redif, Ozgur Ozerdem, and Malabika Basu

This conference paper is available at ARROW@TU Dublin: https://arrow.tudublin.ie/engscheleart/210 


\section{Control of the Shunt Active Power Filter under Non- Ideal Grid Voltage and Unbalanced Load Conditions}

\author{
Samet Biricik \\ Dublin Institute of Technology \\ $\&$ \\ European University of Lefke \\ samet@biricikelektrik.com
}

\author{
Soydan Redif \\ European University of Lefke \\ sredif@eul.edu.tr
}

\author{
Ozgür Cemal Ozerdem \\ Near East University \\ oozerdem@neu.edu.tr
}

\author{
Malabika Basu \\ Dublin Institute of Technology \\ malabika.basu@dit.ie
}

\begin{abstract}
In this study a new method is proposed in order to improve the harmonic suppression efficiency of Active Power Filter for the problems caused by the distorted and unbalanced voltages with unbalanced load currents in control strategy. The proposed control method gives an adequate compensating current reference even for non ideal voltage and unbalanced current conditions. The results of simulation study are presented to verify the effectiveness of the proposed control technique in this study.
\end{abstract}

Index Terms--Active Power Filter, Park Transformation, Clark Transformation, Self Tuning Filter, Unbalanced Load Currents and Voltages.

\section{INTRODUCTION}

Non-linear electrical devices have became common place in industrial and commercial facilities. Computer power supplies rectifier equipment, domestic appliances, adjustable speed drives are some examples of these non-linear loads. These non-linear power electronic loads draw non-sinusoidal currents from ac mains and cause a type of voltage and current distortion called harmonics [1]. These harmonics cause various problems in power systems and in consumer products, such as equipment overheating, blown capacitors, transformer overheating, excessive neutral currents, low power factor, etc. In order to solve these problems, Active Power Filters (APFs) has drawn much attention since the 1970s, because they have excellent compensation characteristics. They are developed to suppress the harmonic currents and compensate for reactive power, simultaneously. For this propose, the power converter of an active power filter is controlled to generate a compensation current that is equal to the harmonic and reactive currents. In order to determine the harmonic and reactive components of the load current, several techniques are introduced in the literature [2]. These strategies applied to APFs play a very important role in the improvement of the performance and stability. The control strategy affects the cost, steady state, and dynamic performances of the filter. The common point of the investigated control techniques is the need of grid voltage measurement [3]. The unbalanced voltages usually occur because of variations and unbalances in the load - arising from differing phases of the load current due to different network impedances for example. Therefore, the dynamic characteristics of the harmonic detection methods would likely be adversely affected without proper consideration of the voltage unbalances, distortions and current unbalances.

In this study, we propose a new method to increase the harmonic suppression efficiency of three phase three wire APF in the case of both non-ideal grid voltage and unbalanced load current condition.

\section{ACTIVE POWER FILTER}

In this study, we consider three-phase systems with variable nonlinear loads. The block diagram of a basic threephase APF connected to a general non-linear load is shown in Fig. 1.

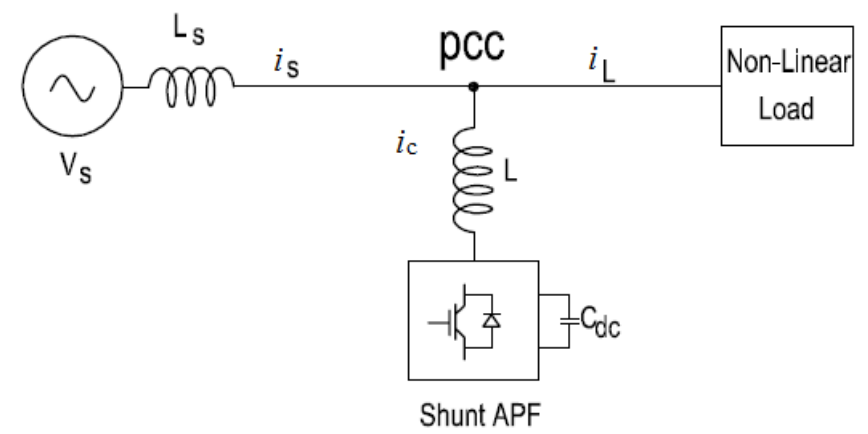

Fig. 1. Block diagram of the APF

The main aim of the APF is to compensate for the harmonics and reactive power dynamically. The APF overcomes the drawbacks of passive filters by using the switching mode power converter to perform the harmonic current elimination. The three-phase load current has a nonunity power factor. Therefore, the current drawn by the possibly reactive load with harmonics and is given by:

$$
i_{L}(t)=i_{1}(t)+i_{h}(t)+i_{q}(t)
$$

where $i_{L}(t)$ is the load current, $i_{l}(t)$ is the fundamental current, $\quad i_{h}(t)$ is the harmonic currents and $i_{q}(t)$ is the reactive current. As is convention, shunt APFs are operated as a current source in parallel with the loads. The power converter of an APF is controlled to generate a compensation current, $i_{c}(t)$, which is equal to the harmonics and opposite phase, i.e., 


$$
i_{c}(t)=-\left(i_{h}(t)+i_{q}(t)\right),
$$

This yields a sinusoidal source current given by

$$
i_{S}=i_{1} \sin (\omega t)
$$

\section{PROPOSED CONTROL Method}

In the proposed control method, first the load currents $\left(i_{a}, i_{b}, i_{c}\right)$ are transformed into the component in the Synchronous Reference Frame coordinate system by using following park transformation:

$$
\left[\begin{array}{l}
i_{d} \\
i_{q} \\
i_{o}
\end{array}\right]=\sqrt{\frac{2}{3}}\left[\begin{array}{ccc}
\cos \theta & \cos \left(\theta-\frac{2 \pi}{3}\right) & \cos \left(\theta+\frac{2 \pi}{3}\right) \\
-\sin \theta & -\sin \left(\theta-\frac{2 \pi}{3}\right) & -\sin \left(\theta+\frac{2 \pi}{3}\right) \\
\frac{1}{\sqrt{2}} & \frac{1}{\sqrt{2}} & \frac{1}{\sqrt{2}}
\end{array}\right]\left[\begin{array}{l}
i_{a} \\
i_{b} \\
i_{c}
\end{array}\right]
$$

where, the angle $\theta$ is the angular position of the synchronous reference. It is a linear function of the angular position of the grid voltages. This angular position can be determined by the aid of a Phase-Locked-Loop (PLL). Therefore, the performance of the control method is dependent on the type of PLL algorithm used. In order to improve the efficiency of the PLL, the three-phase supply voltages $\left(u_{a}, u_{b}, u_{c}\right)$ are transformed using the Clarke (or $\alpha-\beta$ ) transformation into a different coordinate system by using:

$$
\left[\begin{array}{l}
u_{\alpha} \\
u_{\beta} \\
u_{0}
\end{array}\right]=\sqrt{\frac{2}{3}}\left[\begin{array}{ccc}
1 & -\frac{1}{2} & -\frac{1}{2} \\
0 & \frac{\sqrt{3}}{2} & -\frac{\sqrt{3}}{2} \\
\frac{1}{\sqrt{2}} & \frac{1}{\sqrt{2}} & \frac{1}{\sqrt{2}}
\end{array}\right]\left[\begin{array}{l}
u_{a} \\
u_{b} \\
u_{c}
\end{array}\right] .
$$

Then, we obtained two phase voltages processed by the selftuning filter (STF). STF was first used in order to estimate the phase angle of PWM converter outputs [4] and used in [5-19]. In [6], the transfer function is obtained from the integration of the synchronous reference. The transfer function is defined as:

$$
H(s)=\frac{V_{x y}(s)}{U_{x y}(s)}=K_{x} \frac{s+j \omega}{s^{2}+\omega^{2}},
$$

where

$$
V_{x y}(t)=e^{j \omega t} \int e^{-j \omega t} U_{x y}(t) d t
$$

The STF has a magnitude and phase response that is similar to those of a general band-pass filter. Apart from the integral effect on the input magnitude, the STF does not alter the phase of the input, i.e. the input $U_{x y}(s)$ and output $V_{x y}(s)$ have the same phase. Note that in order to have unit magnitude, i.e. $|\mathrm{H}(\mathrm{s})|=0 \mathrm{~dB}$, a constant $K_{X}$ is incorporated in to Eq. 6, that is,

$$
H(s)=\frac{V_{x y}(s)}{U_{x y}(s)}=K_{X} \frac{\left(s+K_{X}\right)+j \omega}{\left(s+K_{X}\right)^{2}+\omega^{2}} .
$$

In the stationary reference, the fundamental components are given by:

$$
\begin{gathered}
\bar{u}_{\alpha}(s)=\frac{K_{1}}{s}\left[u_{a}(s)-\bar{u}_{\alpha}(s)\right]-\frac{\omega}{s} \bar{u}_{\beta}(s), \\
\bar{u}_{\beta}(s)=\frac{K_{1}}{s}\left[u_{\beta}(s)-\bar{u}_{\beta}(s)\right]+\frac{\omega}{s} \bar{u}_{\alpha}(s) .
\end{gathered}
$$

Then, the obtained un-distorted and balanced two phase voltages can be convert to the three phase system by using inverse Clark transformation as given by,

$$
\left[\begin{array}{l}
u_{a} \\
u_{b} \\
u_{c}
\end{array}\right]=\sqrt{\frac{2}{3}}\left[\begin{array}{ccc}
\frac{1}{\sqrt{2}} & 0 & 1 \\
\frac{1}{\sqrt{2}} & \frac{\sqrt{3}}{2} & -\frac{1}{2} \\
\frac{1}{\sqrt{2}} & -\frac{\sqrt{3}}{2} & -\frac{1}{2}
\end{array}\right]\left[\begin{array}{l}
u_{\alpha} \\
u_{\beta} \\
u_{0}
\end{array}\right]
$$

By this method the angular position $(\theta)$ of the source voltages can be determine correctly by using PLL.

Beside this, the un-balanced load currents are also important power quality issue that may reduce the performance of the APF. For this reason, the obtained $i_{d}$ and $i_{q}$ components by (4) are also processed in the proposed control method in order to calculate balanced current components.

$$
\begin{aligned}
& \bar{i}_{d}(s)=\frac{K_{2}}{s}\left[i_{d}(s)-\bar{i}_{d}(s)\right]-\frac{\omega-}{s} \bar{i}_{q}(s), \\
& \bar{i}_{q}(s)=\frac{K_{2}}{s}\left[i_{q}(s)-\bar{i}_{q}(s)\right]+\frac{\omega}{s} \bar{i}_{d}(s) .
\end{aligned}
$$

After obtaining the balanced and undistorted current components, the fundamental and harmonics components of instantaneous currents can be obtain by using (14) and (15), respectively,

$$
\begin{aligned}
& \widetilde{i_{d}}=i_{d}-\bar{i}_{d} \\
& \widetilde{i_{q}}=i_{q}-\bar{i}_{q}
\end{aligned}
$$

In the most of the control method, a low-pass or high-pass filter is used to separate the fundamental and harmonic 
currents. However, there is no need for an additional filter in the proposed control method. Finally, the obtained current harmonic components, from (14) and (15), are then transformed to the three phase converter reference currents using the inverse synchronous transform as given by,

$$
\left[\begin{array}{c}
i_{c a}^{*} \\
i_{c b}^{*} \\
i_{c c}^{*}
\end{array}\right]=\sqrt{\frac{2}{3}}\left[\begin{array}{cc}
\cos \theta & -\sin \theta \\
\cos \left(\theta-\frac{2 \pi}{3}\right) & -\sin \left(\theta-\frac{2 \pi}{3}\right) \\
\cos \left(\theta+\frac{2 \pi}{3}\right) & \sin \left(\theta+\frac{2 \pi}{3}\right)
\end{array}\right]\left[\begin{array}{c}
\tilde{i}_{d} \\
\widetilde{i_{q}}
\end{array}\right]
$$

A block diagram representation of the proposed control method is shown in Fig. 2.

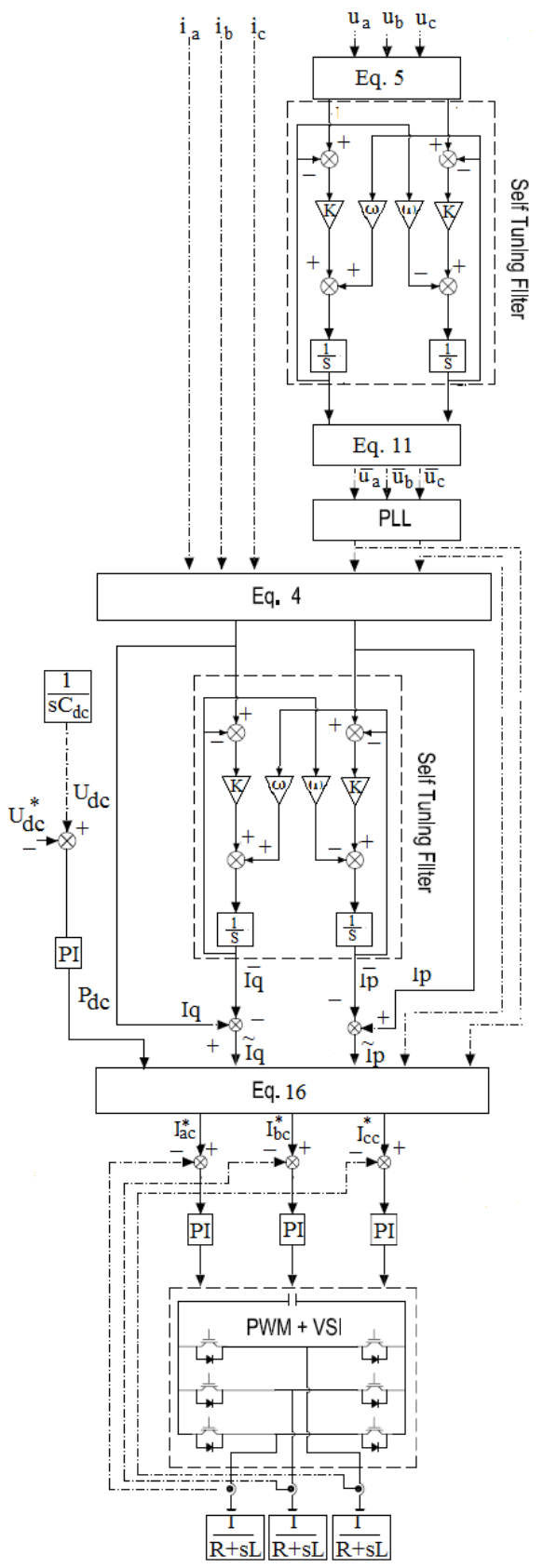

Fig. 2. The block scheme of the proposed control method

\section{SimUlation RESUlts}

The proposed control method is simulated using MATLAB/Simulink and power system block set environment to verify the performance of the system. Three variable RL type non-linear load groups (Load 1, Load $2 \&$ Load 3) are used to see dynamic performances of the APF. Additionally, a linear load (Load 4) is used to create additional unbalance currents condition in the studied system. The used parameters in these work are given in Table I.

TABLE I

PARAMETERS OF THE ANALYZED SYSTEM

\begin{tabular}{|l|l|r|}
\hline Symbol & \multicolumn{1}{|c|}{ Quantity } & \multicolumn{1}{l|}{ Value } \\
\hline $\mathrm{v}_{\mathrm{S},} f$ & Line to Neutral Volt. \& Freq. & $240 \mathrm{~V}, 50 \mathrm{~Hz}$ \\
\hline $\mathrm{Z}_{\mathrm{s}}$ & Grid Impedance & $3 \mathrm{~m} \Omega, 2.6 \mu \mathrm{H}$ \\
\hline $\mathrm{Z}_{\mathrm{c}}$ & Converter Impedance & $20 \mathrm{~m} \Omega, 3 \mathrm{mH}$ \\
\hline $\mathrm{Z}_{\mathrm{L}}$ & Load Impedance & $10 \mathrm{~m} \Omega, 0.3 \mathrm{mH}$ \\
\hline $\mathrm{Load}_{1}$ & Non-Linear Load Res. and Ind. & $16 \Omega, 30 \mathrm{mH}$ \\
\hline Load $_{2}$ & Non-Linear Load Res. and Ind. & $20 \Omega, 30 \mathrm{mH}$ \\
\hline Load $_{3}$ & Non-Linear Load Res. and Ind. & $18 \Omega, 30 \mathrm{mH}$ \\
\hline Load $_{4}$ & Linear Load Res. and Ind. & $40 \Omega$ \\
\hline $\mathrm{C}_{\mathrm{dc}}$ & APF dc Capacitor & $2200 \mu \mathrm{f}$ \\
\hline $\mathrm{U}_{\mathrm{dc}}$ & dc- Link Voltage & $750 \mathrm{~V}$ \\
\hline $\mathrm{K}_{\mathrm{p}} \& \mathrm{~K}_{\mathrm{i}}$ & Proportional \& Integral Gain & $0.88 \& 78.96$ \\
\hline $\mathrm{K}_{1} \& \mathrm{~K}_{2}$ & STF Gain & $100 \& 40$ \\
\hline $\mathrm{f}_{\mathrm{s}}$ & Switching Frequency & $14 \mathrm{kHz}$ \\
\hline
\end{tabular}

In this study, the Total Harmonic Distortion (THD) of the grid voltages in each phase are $10.80 \%, 12.79 \%$ and $8.13 \%$. The voltages between phase to neutral in each phase are $240.4 \mathrm{~V}, 226.3 \mathrm{~V}, 247.5 \mathrm{~V}$. The grid voltage waveform can be seen in Fig. 3. Moreover, the THD of the load currents in each phase are $11.76 \%, 13.21 \%$ and $15.11 \%$ while the RMS currents are $39.22 \mathrm{~A}, 35.34 \mathrm{~A}, 35.42 \mathrm{~A}$. In the second load combination the currents are increased to $49.31 \mathrm{~A}$, $35.33 \mathrm{~A}, 43,96 \mathrm{~A}$. The current waveform of the load groups can be seen in Fig. 4.

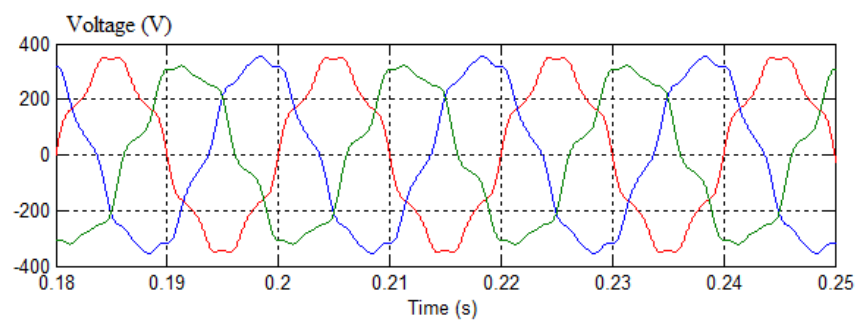

Fig. 3. Three phase unbalanced and distorted (non-ideal) grid voltage

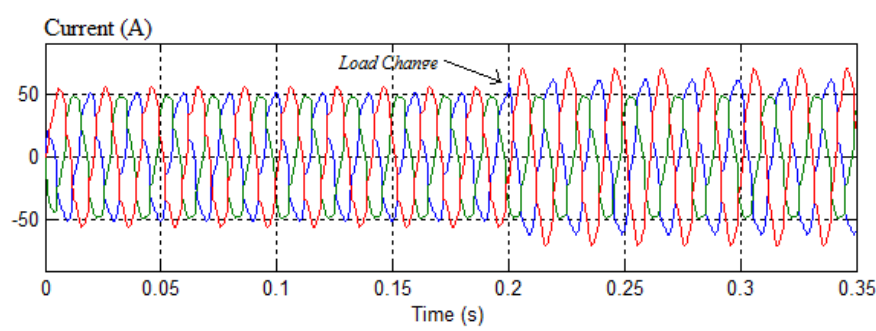

Fig. 4. Unbalanced varying load current under non-ideal voltage condition. 
After converting the three phase voltages to two phase coordinate system $(\alpha-\beta)$ as described in (5), the grid voltages are processed by using STF as given in (9) and (10). Then, the obtained undistorted and ideal two phase voltage waveforms are transformed to three phase voltage waveforms by using inverse Clarke transformation (see Eq.11). Related waveforms to these processing are giving in Fig. 5.
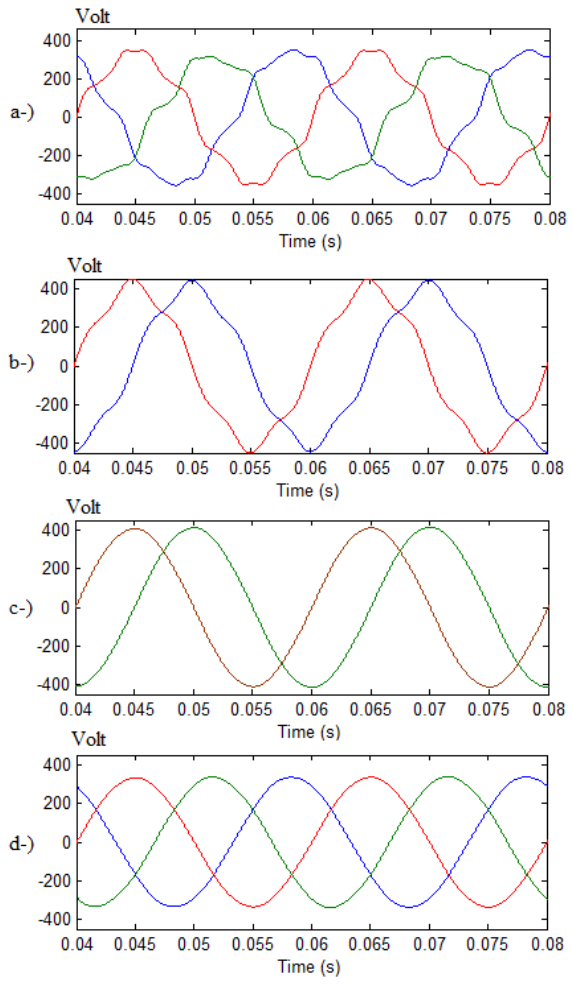

Fig. 5. Voltage waveforms, a-) Three phase unbalanced and distorted grid voltages, b-) Grid voltages after transformation to $\alpha-\beta$ ( at the input of $S T F$ ), c-) The obtained balanced and undistorted two phase voltage waveforms (at the output of STF), d-) The obtained balanced and undistorted three phase voltage waveforms (at the input of PLL).

After obtaining the correct angular position of the synchronous reference, the $i_{d}$ and $i_{q}$ components are calculated by using park transformation as given in (4). Second STF is designed as described in (12) and (13) to process $i_{d}$ and $i_{q}$ components. By this method, balanced $i_{d}$ and $i_{q}$ components are obtained.

In order to compensate converter losses the DC-link capacitor voltage is processed by using conventional PI regulator. The DC-link voltage waveform at the capacitor terminal is given in Fig. 6.

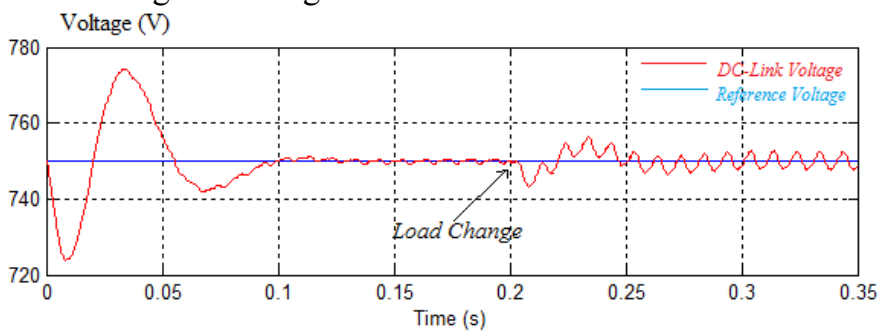

Fig. 6. DC-link terminal voltage with the proposed control method
Moreover, the harmonic components are subtracted from fundamentals to obtain two phase converter reference currents. For this, additional low pass filter or high pass filter is not used. Then, the obtained two phase reference current signals are converted to three phase as given in Fig. 7 by using (16).

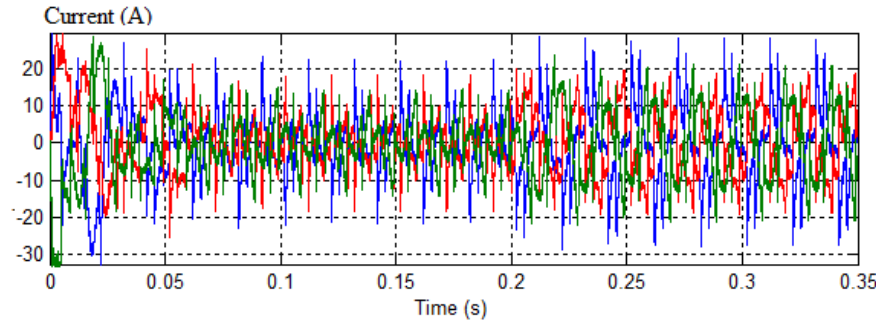

Fig. 7. Three phase converter currents

Finally, the grid current waveform is obtained as given in Fig. 8. The THD of the grid currents are reduced from $13 \%$ to around $2 \%$.

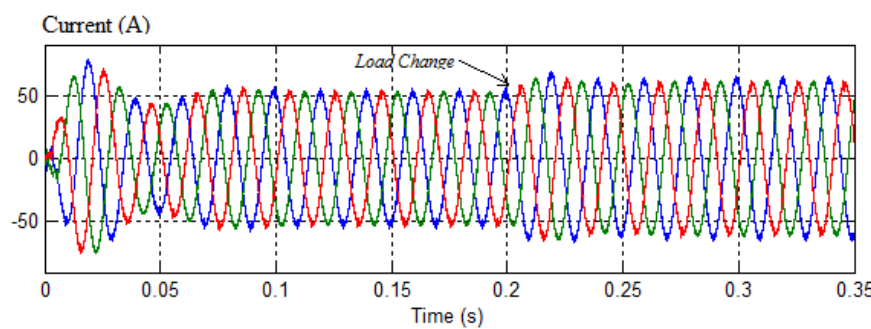

Fig. 8. Grid current after filtering by proposed control method under distorted and un-balanced grid voltage with unbalanced load conditions

\section{CONCLUSION}

In this paper, we have considered to design a control method in order to generate correct reference current signal to satisfy the requirements of harmonic suppressing and reactive power compensation for the unbalanced nonlinear loads combination under case of non-ideal grid voltage conditions. In the propose method, the distorted and unbalanced voltages first processed by using Self Tuning Filter to determine the correct angular positions. Then second STF is used to extract balanced load current waveforms after obtaining the fundamental and harmonic components of instantaneous currents by using park transformation. In this study, additional low-pass or high-pass filter is not used to extract harmonic components from the fundamental. The simulation studies shows that the proposed control technique gives an adequate compensating current references.

\section{ACKNOWLEDGEMENTS}

The authors acknowledge the financial support by the European Union under contract no: 2012/307-675.

\section{REFERENCES}

[1] W. M. Grady, S. Santoso, "Understanding power system harmonics", IEEE Power Eng., Rev. 21, pp. 8-11.

[2] B. Singh, K. Al-Haddad, K, A. Chandra, "A review of active filters for power quality improvement", IEEE Transaction on Industrial Electronics., vol. 46, no. 5, pp. 960-971, 1999. 
[3] N. Mariun, A. Alam, S. Mahmod, H. Hizam, "Review of control strategies for power quality conditioners", PECon 2004, Power and Energy Conference, vol., no., pp. 109- 115, 29-30 Nov. 2004.

[4] H. S. Song, "Control scheme for PWM converter and phase angle estimation algorithm under voltage unbalance and/or sag condition", Ph.D. thesis in Electronic and Electrical Engineering. South Korea, 2000.

[5] M. Abdusalam, P. Poure, S. Saadate, "A New Control Scheme of Hybrid Active Filter Using Self-Tuning-Filter,” POWERENG 2007 International Conference on Power Engineering, Energy and Electrical Drives, 2007, vol., no., pp.35-40, 12-14 April 2007.

[6] S. Karimi, P. Poure, S. Saadate, "High performances reference current generation for shunt active filter under distorted and unbalanced conditions", IEEE -PESC Power Electronics Specialists Conference, vol., no., pp.195,201, 15-19 June 2008.

[7] M. Abdusalam, P. Poure, S. Saadate, "Hardware implementation of a three-phase active filter system with harmonic isolation based on selftuning-filter", IEEE-PESC 2008, Power Electronics Specialists Conference, vol., no., pp.2875,2881, 15-19 June 2008.

[8] M. Abdusalam, P. Poure, S. Karimia, S. Saadatea, "New digital reference current generation for shunt active power filter under distorted voltage conditions", Electric Power Systems Research, vol. 79, pp 759-76, 2009

[9] N. Gupta, S. P. Dubey, S. P. Singh, "PIL based control algorithm for three-phase four-wire active filter for reactive and harmonic compensation under distorted supply", 2010 Joint International Conference on Power Electronics, Drives and Energy Systems, (PEDES) \& 2010 Power India, , vol., no., pp.1,6, 20-23 Dec. 2010.

[10] E. Samedaei, H. Vahedi, A. Sheikholeslami, S. Lesan, "Using STFPQ algorithm and hysteresis current control in hybrid active power filter to eliminate source current harmonic", Power Quality Conference (PQC), pp.1-6, 2010.

[11] E. Samadaei, S. Lesan, S. M. Cherati, "A new Schematic for hybrid active power filter controller," 2011 IEEE Applied Power Electronics Colloquium (IAPEC), vol., no., pp.143,148, 18-19 April 2011.

[12] S.Biricik, O.C.Ozerdem, S.Redif and M.O.I.Kmail, "Novel Hybrid Active Power Filter Structure to Compensate Harmonic Currents and Reactive Power", MELECON 2012 - 16th IEEE Mediterranean Electro-technical Conference, 25-28 Mart 2012, Tunisia.

[13] O.C.Ozerdem, S.Biricik "Control of Shunt Active Filter under Nonideal Grid Volage and Un-Balanced Load Conditions", Electrical, Electronics and Computer Engineering, (ELECO 2012), 29 Nov.-01 Dec. 2012, Turkey (in Turkish).

[14] A. Ghamri , M. T. Benchouia \& A. Golea "Sliding-mode Control Based Three-phase Shunt Active Power Filter", Simulation and Experimentation, Electric Power Components and Systems, 40:4, 383$398,2012$.

[15] G. Adam, A. G. Stan, G. Livint, "An adaptive hysteresis band current control for three phase shunt active power filter U sing Fuzzy logic", 2012 International Conference and Exposition on Electrical and Power Engineering (EPE), vol., no., pp.324,329, 25-27 Oct. 2012.

[16] A. Benaissa, B. Rabhi, M. F. Benkhoris, A. Moussi, J. Le Claire, "Fuzzy logic controller for five-level shunt active power filter under distorted voltage conditions," IECON 2012 - 38th Annual Conference on IEEE Industrial Electronics Society, vol., no., pp.4973,4978, 25-28 Oct. 2012.

[17] I. Ghadbane, A. Ghamri, M. T. Benchouia, A. Golea, "Three-phase shunt active power filter for power improvement quality using Sliding Mode Controller", 2nd International Conference on Communications, Computing and Control Applications (CCCA), vol., no., pp.1,6, 6-8 Dec. 2012.

[18] S.Biricik, O.C.Ozerdem, S.Redif and M.O.I.Kmail, "Performance Improvement of Active Power Filter under Distorted and Unbalanced Grid Voltage Conditions", Journal of Electronics and Electrical Engineering, ISSN 1392 - 1215, Vol. 19, No.1, 2013 pp 35-39.

[19] M. C. Ben Habib, E. Jacquot, and S. Saadate. "An advanced control approach for a shunt active power filter", presented at Int. Conf. Renovable Energy Power Quality. 